\title{
Damage to Camel Meat by Onchocerca Fasciata Nodules in Jordan
}

\author{
FK Al-Ani ${ }^{1}$ and $\mathrm{Z} \mathrm{Amr}^{2}$ \\ ${ }^{1}$ College of Applied \& Health Sciences, A'Sharqiyah University, Oman \\ ${ }^{2}$ Department of Biology, Jordan University of Science and Technology, Jordan
}

Submission: May 18, 2019; Published: June 14, 2019

*Corresponding author: FK Al-Ani, Biology Unit, College of Applied \& Health Sciences, A'Sharqiyah University, Sultanate of Oman

\begin{abstract}
Like other livestock camels are exposed to and affected by a range of Onchocerca species. Of particular regional importance to camels are the Onchocerca fasciata causing worm nests in the ligamentum nuchae and subcutaneous tissues of the body. Onchocerciasis also infects human but the caused species reported is Onchocerca volvulus that has been reported mainly in Africa, with additional foci in Latin America and the Middle East. Symptoms include severe itching, bumps under the skin, and blindness. The parasite worm is spread by the bites of a black fly of the Simulium type. To study the prevalence of the damage in camel meat by Onchocerca fasciata infection a total of 97 camels slaughtered at Ramtha slaughterhouse of Jordan were studied. After slaughtering the skin is removed and gross examination was performed on the subcutaneous tissues, muscles, ligamentum nuchae, blood vessels and internal organs. The presence of cutaneous nodules was carefully examined and then opened. Living parasites were removed and sent to the Department of Parasitology for diagnosis. The gross damage to the local tissue was described and photographed. Selectively tissue samples were collected, preserved in buffered $10 \%$ formalin solution and processed by standard histopathological techniques and stained with haematoxylin and eosin (H\&E).
\end{abstract}

Results indicated that out of 97 camels examined 8camels were infected (8.24\%) with Onchocerca fasciata. Most of older camels (over 4 years) had higher infection rate while younger one (1 to 2 years old) were not seen infected. Following slaughtering parasite nodules were found grossly visible on ligamentum nuchae as well as in the subcutaneous tissues of the abdominal cavity on the muscles of abdomen including the rectus abdominis muscle and the external oblique abdominis muscle. Also, nodules of the parasite were seen in the head region close to the eye in the cervicoscutularis muscle, under the ear in the zygomaticoscutularis muscle, and in the occipitofrontalis muscle. Because of the damage in the camel meat by parasite nodules, 6 carcasses were passes the inspection with local condemnation of the affected parts. Two carcasses were total condemned because of the extensive nodule involvements of the body.

Keywords: Onchocerciasis; Onchocerca fasciata; Camel meat; Jordan

\section{Introduction}

Cutaneous onchocerciasis is a filarial parasitic infection of animals, with world-wide distribution, caused by different species of Onchocerca. The adults of Onchocerca cervicalis are found in the ligamentous tissue adjacent to the nuchal attachment of the thoracic vertebral spinous processes and in and around the supraspinous bursa of horses [1]. In cattle, O. gutturosa locates in the ligamentum nuchae, and 0 . lienalis in the gastrosplenic ligament [2]. In camels three species of Onchocerca have been reported. These include 0 . fasciata, 0 . armillatta and 0 . gutturosa [3-5]. One investigator [6] confirmed the aortic onchocercosis due to 0 . armillata in $45(41 \%)$ out of 109 Sudanese camels. Other authors who surveyed the prevalence of onchocercosis in camels found 0 . fasciata in $2.75 \%$ of camels in Egypt [7], 33.3\% in camels in Saudi Arabia [8]. The purpose of our investigation was intended to record the epidemiological and pathological changes observed on camel meat infected with Onchocerca fasciata nodules.

\section{Materials and Methods}

During a 1-year period, a total of 97camels slaughtered were examined for camel onchocerciasis. The camels were slaughtered at a local slaughterhouse at Ramtha province and the owners replaced the herds by buying camels of different ages from animal auctions located in different parts of Jordan. All camels are raised for slaughtering purposes. Routine clinical examinations of all camels were performed before slaughtering with special emphasis on the skin. Following slaughtering samples were collected one time a week in which 3 to 8 camels were slaughtered weekly over 12 months. After slaughtering the skin is removed and gross examination was performed on the subcutaneous tissues, muscles, ligamentum nuchae, blood vessels and internal organs. The presence of cutaneous nodules was carefully examined and then opened. Living parasites were removed and sent to the Department of Parasitology for diagnosis. The gross damage to the 
local tissue was described and photographed. Selectively tissue samples were collected, preserved in buffered $10 \%$ formalin

solution and processed by standard histopathological techniques and stained with hematoxylin and eosin (H\&E) (Figure 1).

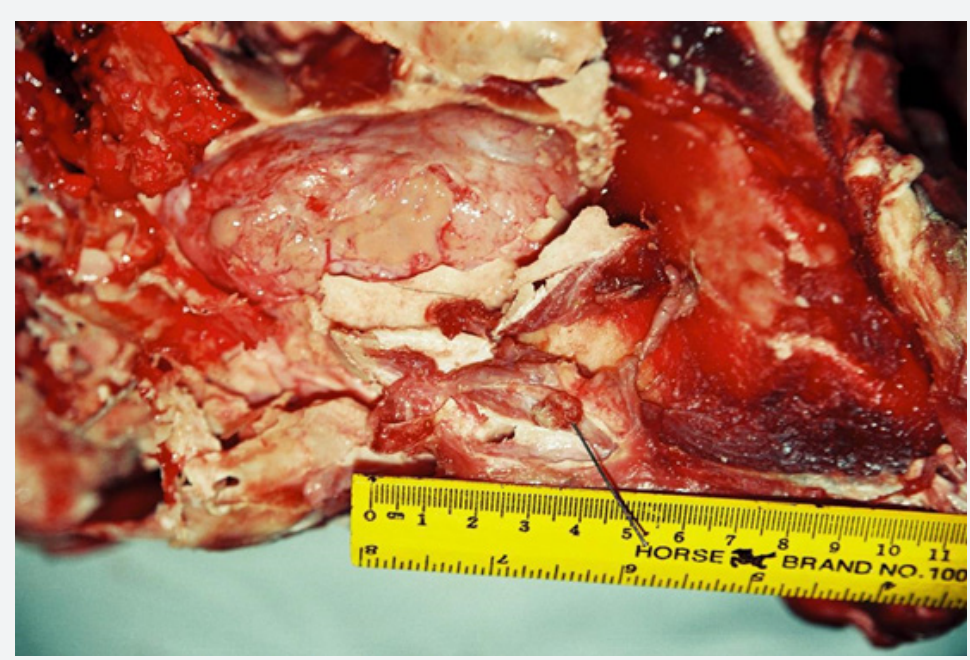

Figure 1: Onchocerca nodules in the subcutaneous tissues of a 7-year-old female-camel after slaughtering.

Results

Out of 97 camels examined 8 camels were infested with Onchocerca fasciata (8.24\%). In living animals no clinical signs of onchocerciasis were seen except two camels showed cutaneous swelling on the ventral abdominal wall. Whereas following slaughtering parasite nodules were found grossly visible on ligamentum nuchae as well as in the subcutaneous tissues of the abdominal cavity on the muscles of abdomen including the rectus abdominis muscle and the external oblique abdominis muscle. Also, nodules of the parasite were seen in the head region close to the eye in the cervicoscutularis muscle, under the ear in the zygomaticoscutularis muscle, and in the occipitofrontalis muscle. However, vision and hearing were not affected. No parasites lesions were seen in the blood vessels or internal organs. On palpation of the nodules, they were firm and of variable sizes. On incision, most of the nodules were filled by living parasites with little fluid. Some nodules were so hard and contained degenerated parasites with calcification. Both male and female parasites were present in the nodules. Most parasite still alive and move freely in the nodules. Parasite refereed to parasitology Department came up with the diagnosis of Onchocerca fasciata.

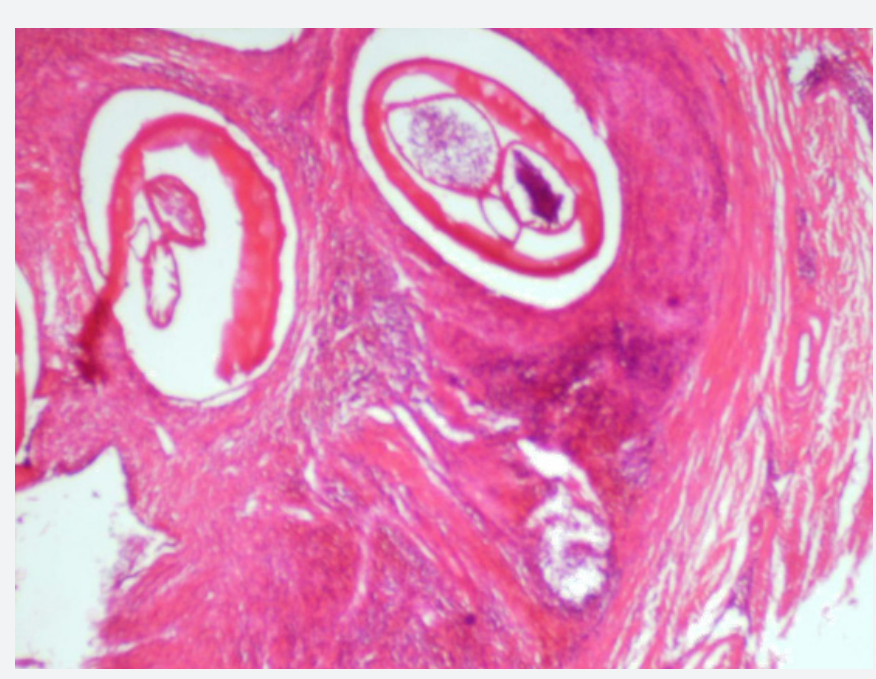

Figure 2: Histological section through the gravid female of $O$. fasciata in tissue stained with H\&E. Several cross-sections of the coiled worm are seen with the presence of microfilariae in the uterine tubes.

Histological changes were as desquamation of the epithelial cells with infiltration of different types of leukocytes such as the neutrophils, eosinophils and lymphocytes in the inflamed areas. Most of these worms are fertile females with microfilariae in the uterus. Inflammatory infiltration of varying composition is present around live and degenerated worms (Figure 2). In the early stages, lymphocytes, eosinophils and histocytes are prominent, but later, eosinophils decrease while plasma cells and giant cells increase in number. Heavy infiltrations by neutrophils occur in nodules containing degenerated or dead worms. 


\section{Discussion}

Three of species of the nematode genus Onchocerca occur in the subcutaneous tissues of camel throughout the world [3]. $O$. fasciata is a nodule forming filaral nematodes in the ligamentum nuchae and other parts of the body, especially the subcutaneous tissues of the head and neck regions. In the present study $8.24 \%$ of the camels examined have parasite nodules on ligamentum nuchae as well as in the subcutaneous tissues of the abdominal cavity on the muscles of abdomen including the rectus abdominis muscle and the external oblique abdominis muscle. Also, nodules of the parasite were seen in the head region close to the eye in the cervicoscutularis muscle, under the ear in the zygomaticoscutularis muscle, and in the occipitofrontalis muscle. It is reported in camels in Saudi Arabia, Kuwait, Sudan, and Australia [9-11]. O. fasciata and 0. gutturosa occur in the subcutaneous tissue of camels and cattle. O. armillata occurs in the aorta of camel as tortuous tunnels of parasitic tracks readily visible in the intimal surface of the vessels [6].

O. cervicalis occurs in the ligmantum nuchae and subcutaneous tissues of the neck, and in some cases, the flexor tendons and ligaments of the fetlock of horses. 0 . volvulus occurs in the sub of human [12]. The adult parasites reside in subcutaneous tissues, whereas microfilarias circulate in the blood. Life cycle is indirect and the intermediate host and vector may be one of a number of species of Culicoides. The parasite microfilariae are of 245 to $294 \mu \mathrm{m}$ long and are present in the skin and connective tissue spaces. Upon biting an infected camel, the Culicoides ingests microfilariae, which have a developmental cycle in the insect similar to that of other filarial larvae, transforming into infective forms that may enter a new host when the Culicoides again takes a blood meal [13]. After introduction into the new host, the developing worms wander through the subcutaneous tissues and then settle down, usually in groups of two or more; most worms finally become encapsulated. Onchocerca gutturosa occurs in the ligamentum nuchae of cattle and camels. Males are 2.9 to $3.0 \mathrm{~cm}$ and females $6.0 \mathrm{~cm}$ long. $O$. gibsoni occurs in cattle, zebu and camels in Asia, Australia and South Africa [2]. The worms are usually found in nodules, which may occur especially on the brisket and the external surface of the hind limbs. The male is 30 to $53 \mathrm{~mm}$ long while the female 140 to $190 \mathrm{~mm}$. Life cycle is indirect and the intermediate host is midge Culicoides pungens.

Various nonspecific skin changes have been observed in association with the filarial nematodes. It is not clear whether the parasites induced the dermatitis or the lesions are due to a hypersensitivity reaction to antigens released by dying microfilaria [14]. Camels affected by onchocerciasis usually develop no clinical signs and generally the parasite nodules are seen at slaughtering or postmortem examination. If the subcutaneous nodules are large, detection of these nodules by palpation is possible. Diagnosis is by identification of the microfilariae in skin snips. Biopsy of the subcutaneous nodules may be taken and histopathological sectioning of these nodules reveals the presence of worms enclosed in smooth fibrous capsules. Fibrinoid material has been associated with immune complex deposition. For this reason, Schmidt suggested that an immune reaction between the host and the Onchocerca species or its metabolic products results in the host inflammatory response adjacent to the parasites [1517]. Slightly higher than one-tenth of the camels in this study had evidence of adult Onchocerca fasciata infection. This is significantly lower than the $76.9 \%$ prevalence previously reported for camel onchocerciasis in Saudi Arabia.

\section{Conclusion}

This study has shown that camels in Jordan are at risk of being infected by onchocerciasis. This may cause economic loss to camel industry due to meat rejection of the infected carcasses. Therefore, occurrence of the infection can be reduced by treatment the camels with Ivermectin and controlling fly population as the vector of the parasite.

\section{Acknowledgements}

Financial assistance from Jordan Bidia Research and Development Center is highly appreciated.

\section{References}

1. Fadock VA (1984) Parasitic skin diseases of large animals. Vet Clinic North Am 6: 3-26.

2. Soulsby EJ (1982) Helminthes, Arthropods, and Protozoa of Domestic Animals. (6 $6^{\text {th }}$ edn), Bailliere Tin Dall, London, UK, pp. 323-327.

3. El Bihari S (1985) Helminths of the camel: a review. Br Vet J 141: 315326.

4. Schillhorn Van Veen TW, Bello SI, Folaranmi DO (1976) Onchocerca armillata (Railliet and Henry, 1909) from a new host, Camelus dromedari. Rev Elev Med Vet Pays Trop 29: 227-228.

5. Nasher AK (1986) Incidence and intensity of Onchocerca fasciata (Railliet and Henry, 1910) in local camels in Saudi Arabia. Ann Parasitol Hum Comp 61: 77-80.

6. Awad MA, Osheik AA, Tageldin MH, Zakiam AM (1990) Note on Onchocerca armillata in the Sudanese camel (C. dromedarius). A histological and anatomo-pathological approach. Rev Elev Med Vet Pays Trop 43: 345-348.

7. El-Massry AA, Derbala AA (2000) Evidence of Onchocerca fasciata (Filarioidea: Onchocercidae) in camels (Camelus dromedarius): I-prevalence, nodular lesions appearance and parasite morphology. Vet Parasitol 88: 305-312.

8. Ghandour AM, Al-Amoudi AA (1991) Onchocerca fasciata and its nodule development in camels in Saudi Arabia. Vet Parasitol 39: 67-77.

9. Holdsworth PA, Moorhouse DE (1985) Onchocerca gutturosa in an Australian camel. Aust Vet J 62: 201-202.

10. Hussein HS, el Mannan AM, el Sinnary K (1988) Onchocerca armillata (Railliet and Henry, 1909) and Onchocerca gutturosa (Neumann, 1910) in camels (Camelus dromedarius) in the Sudan. Vet Res Commun 12: 475-480.

11. McFrederick QS, Haselkorn TS, Verocai GG, Jaenike J (2013) Cryptic Onchocerca species infecting North American cervids, with implications for the evolutionary history of host associations in Onchocerca. Parasitology 140: 1201-1210.

12. Murdoch ME, Hay RJ, Mackenzie CD, Williams JF, Ghalib HW, et al. (1993) A clinical classification and grading system of the cutaneous changes in onchocerciasis. Br J Dermatol 129: 260-269. 
13. El-Bahnasawy MM, Morsy AT, Morsy TA (2015) The arthropod-borne onchoceriasis: is it deserved to be neglected? J Egypt Soc Parasitol 45: 639-654.

14. Ali MM, Baraka OZ, AbdelRahman SI, Sulaiman SM, Williams JF, et al. (2003) Immune responses directed against microfilariae correlate with severity of clinical onchodermatitis and treatment history. J Infectious Dis 187: 714-717.

15. Abdul-Salam J, Al-Taqui M (1995) Seasonal prevalence of Onchocer$c a$-like microfilaria in camels in Kuwait. Journal of Egyptian Society of Parasitology 25: 9-24.

This work is licensed under Creative Commons Attribution 4.0 License

DOI: 10.19080/JDVS. 2019.12 .555840
16. Cheema AH, El-Bihari S, Ashour NA, Ali SS (1984) Onchocerciasis in camels (Camelus dromedarius) in Saudi Arabia. J Helminthology 58: 279-285.

17. El Sinnary K, Hussein HS (1982) Onchocerca gutturosa (Neumann), in camels (Camelus dromedaries) in the Sudan. Annals Trop Med Parasito 75: 469-470.

\section{Your next submission with Juniper Publishers} will reach you the below assets

- Quality Editorial service

- Swift Peer Review

- Reprints availability

- E-prints Service

- Manuscript Podcast for convenient understanding

- Global attainment for your research

- Manuscript accessibility in different formats

( Pdf, E-pub, Full Text, Audio)

- Unceasing customer service

Track the below URL for one-step submission https://juniperpublishers.com/online-submission.php 